\title{
'Personal child health records' held by parents
}

'By comparison with the situation 50 or 100 years ago, women are well educated; they are able to acquire and weigh up knowledge and advice from a wide variety of sources, including friends and relatives, books and magazines. They are highly motivated and will seek help if and when they need it from health staff, and are also willing to use services if requested to do so'. 1

The idea is a simple one-that the medical records of a child are primarily to aid the exchange of information between professionals whenever they undertake to help care for a child. The parents are the professionals who carry out most of the health and illness care of an individual child and to aid them in this they need to have full and immediate access to all the relative information.

\section{Are medical records primarily to aid in the exchange of} information between professionals?

There are of course many reasons for keeping records-legal, epidemiological, research, etc-but these are, and should remain, secondary to meeting the need to share information so as to provide optimal health and illness care to an individual. This optimal care will, very occasionally, include health care professionals withholding information from one another and in doing so they have to undertake the responsibilities that arise from such an action. Parents certainly, under some conditions, may withhold information about a child from the medical professionals, and on occasions the reverse will also be true. In both cases the carer may have the child's best interest at heart, or, although they may not realise or admit it, their own best interests at heart. Examples of the latter are easy to find: the parent may not want to reveal worries about child abuse because they think it is being carried out by their spouse, and a doctor may not want to reveal her worry about a child being abused to the parent because of the furious reaction that this may engender.

However to aid information exchange, secondary considerations need to be considered second.

Who are the health professionals who look after the health and illness care of children?

Children are primarily looked after on a 24 hour a day, seven days a week, 365 days a year basis by their parents (yes, there are exceptions, but they are exceptions). The evidence is that most parents are devoted to maintaining the health of their children. ${ }^{2}$ Hardly surprising as the continuation of the human race depends on it.

Giving parent's diaries to keep about how they deal with their children's illness shows that in most cases these are managed by parents without referring to a medical professional. ${ }^{2}$ However children's health and their illnesses are in the minority of cases also coped with by relatives, childminders, teachers, nurses, doctors, playgroup leaders, next door neighbours, etc. All these people may be aided in doing this by access to the relative medical information.

\section{Where do health professionals deal with health and illness in children?}

The majority of health and illness in children is looked after by the parents at home. However there are a large number of other places that the child may be cared for: including at the childminder, playgroup, nursery, school, doctor's surgery, child health clinic, a hospital accident and emer- gency department, hospital inpatients' and outpatients' departments, etc. Access to records are needed in all these places.

How are these needs for access to information about a child best met?

The needs can be met by a 'personal child health record' held by the parents. Available research shows that (i) parents want to hold their own record ${ }^{4}$; (ii) do not loose the record significantly more than the medical system does ${ }^{5}$; (iii) general practitioners and health visitors like the system; (iv) that the system is particularly valuable with mobile families such as service and travelling families ${ }^{6}$; and (v) that parent held records are filled in better than clinic held records. ${ }^{5}$

What does the 'national' record consist of?

It is A5 horizontal size and has a bright red plastic cover (all the easier to find it with) with two clear plastic pockets in the inside. There are 50 loose leafed punched sheets fastened in the record using a white soft plastic covered metal rod so that pages can be easily added (or taken out). The details on these pages include information about the child's address, doctor, health visitor, major health problems, family history, birth details, clinic/home visits, immunisations, growth charts, routine reviews, all consultations, and a help section including teeth care, feeding advice.

There are pages of questions for parents to fill in about their own health and about their own observations of their child's health and development. There are also 'injury prevention' messages throughout the record at development appropriate intervals to be discussed between the primary health care team and the parents.

What have been some of the main problems encountered since launching a national record?

One of the main problems was agreement over the overall contents of the record. A national version was agreed upon and the details published in a report by the original working party made up of representatives from the Royal College of General Practitioners, the British Paediatric Association, the British Medical Association, and the Health Visitors Association. ${ }^{7}$ The working party accepted that there would always be argument over the contents. However the record recommended is loose leafed and can be adapted to the needs of local service providers and individual children. The contents are under constant revision and the reconvened national working party will be reporting on the new recommended version in the middle of 1992 .

Then there is the issue concerning who actually 'owns' the record. The legal, medical, and ethical issues that surround this question are complex and still under discussion with the Department of Health. Meanwhile some districts categorically state that the record belongs to the parents, others to the state, others to the local district health authority.

Also who should pay for the record? The Department of Health, although fully supporting the concept of personal child health records held by parents, has stated that it does not see itself responsible for financing the record. This has been left up to the ingenuity of local districts. Getting the parents, the district, the family health services authority, or 
drug companies to pay-have all been looked at and variously used.

Linking the information in the record to various computer systems is a problem because there is not a single standard computer system in all districts. Luckily most districts use the National Child Health Computer System, but others do use alternatives. The design of certain of the pages concerned with the routine checks on the child and the immunisations done have been made similar to the 'screens' on the national computer system, with non-carbonated copies of these pages being sent centrally for the information to be put onto the district health authority computer system. Problems arise however as this compromises the records' 'user friendliness' for parents.

There is the question as to whether there is a need to keep parallel records. General practitioners are legally bound to keep there own standard practice records on their own patients. What records other professionals have to keep (health visitors, community doctors, therapists, etc) depends on the needs of individual practitioners in their care of the individual children. Where there is a question of possible or actual child abuse it is recommended that parellel records should automatically be kept, but that the parents should be informed of this.

\section{What of the future?}

With recent recommendations from the Department of Health and the Foundation for the Study of Infant Deaths consideration will now be given to having a page/pages devoted to the prevention of sudden infant death syndrome, including information concerning the position a child is put down to sleep and the hazards of smoking. Sometime in the future, after further research, consideration may also be given to having a modified system of aiding parents to recognise significant signs and symptoms of illness in their children.

Pages for the record concerning the health and development of school age children are under consideration. There are, however, a number of problems. First is the whole question of the future provision of school health services. Second is the fact that sometime during the school age years, the focus of responsibility for health shifts from the parents to the child. Third is the lack of available research showing the value of detailed health promotion in this age group. All this also raises the issue as to when the record should be given to a young adult, and for the more distant future, whether the record could continue to be used on into adult life.

A further proposition for the future is to keep a national 'library' of different pages for the record as developed by different people in different districts. The need for such a library containing all the variations on the national record has become obvious, but who should keep it and how it should be financed has yet to be settled.

There is also the need for further research to look at the costs, benefits, and drawbacks to further developments in the record. For instance new national centile charts are being drawn up in the light of the evidence that the present Tanner and Whitehouse charts are outdated. These new charts will be completely redesigned using information available from the various present databases concerned with the growth of children.

In conclusion, the development of a national personal child health record far from being a 'one off' concept is an ongoing dynamic entity that consumes much time and work, but also offers great rewards as long as it is recognised that the ideal should not stand in the way of putting into practice what is merely a great deal better than what was there before. How well it works does not only depend on its use by parents but even more so on its use by, and the value attached to it by, doctors and nurses both in the community and hospital, If it is valued by them, then the parents will value it too, will not loose it, and will bring it with them to all contacts with the primary and secondary care providers to share the information so as to ensure the better care of their child.

Community Health Offices,

AIDAN MACFARLANE

\section{Radcliffe Infirmary,} Oxford $O X 26 H F$

1 Mayall B. Child Health Care. Living with children, working for children. London: Heinemann Nursing, 1989.

2 Spencer NJ. Parents recognition of the ill child. In: Macfarlane A, ed. Progress in child health. Vol 1. Edinburgh: Churchill Livingstone, 1984. 3 Mayall B. Keeping children healthy. London: Allen and Unwin, 1986.

4 Sefi S, Macfarlane A. Child health clinics: why mothers attend. Health Visito 1985;58:129-30.

5 Saffin K, Macfarlane A. How well are parent held records kept and completed. Br 7 Gen Pract 1991;41:249-51.

6 Miller SA StJ. A trial of parent held child health records in the armed forces. BMF 1990;300:1046

7 British Paediatric Association. Report of the joint working party on professional and parent held records used in child health surveillance. London: British Paediatric Association, 1990.

\section{Medulloblastoma}

The treatment of childhood brain tumour is a subject that represents a major challenge and yet remains a major frustration to the paediatric oncologist. Medulloblastoma is a rare, highly malignant tumour usually arising in the vermis of the cerebellum. It accounts for approximately $30 \%$ of childhood brain tumours, or one child per 150000 per year ( 80 cases year in the UK). The tumour can occur at any age through childhood with a peak occurring around the age of 5 years. Males are slightly more often affected than females. Medulloblastoma is therefore a rare diagnosis in the majority of paediatric units and is a tumour of sufficient rarity that international cooperation has been essential to study possible treatment advances.

The histological origin of the medulloblastoma is uncertain. It may arise from embryonal rest cells left behind after the development and subsequent disappearance of the outer granular layer of the cerebellum in the roof of the fourth ventricle. An alternative theory is that medulloblastoma originates from undifferentiated cells in the subependymal region in the roof of the fourth ventricle. These cells have the ability to differentiate into neuronal and glial cells and are found in all ages and in various areas of the brain, in particular in the area of the fourth ventricle, in the cerebellum, and in those parts of the pallidum, nucleus caudatum, and thalamus that are next to the ventricles. Medulloblastoma-like tumours arise in these areas and this observation has led Rorke to suggest that the term 'primitive neuroectodermal tumour' (PNET) should be applied to all of these tumours. ${ }^{1}$ Other pathologists however disagree with this view and suggest that the term medulloblastoma should 